\title{
The Effect of Using Storytelling Strategy on Students' Performance in Fractions
}

\author{
Charalambos Lemonidis ${ }^{1} \&$ Ioanna Kaiafa ${ }^{1}$ \\ ${ }^{1}$ School of Primary Education, University of Western Macedonia, Florina, Greece \\ Correspondence: Ioanna Kaiafa, School of Primary Education, University of Western Macedonia, Florina, \\ Greece. E-mail: j.kaiafa@windowslive.com
}

Received: January 22, 2019

Accepted: February 15, 2019 Online Published: March 3, 2019

doi:10.5539/jel.v8n2p165

URL: https://doi.org/10.5539/jel.v8n2p165

\begin{abstract}
Research findings in the field of Mathematics Education emphasize that storytelling is an effective instructional tool in the teaching of mathematics, as it provides a meaningful context that attracts students' interest and makes learning a pleasant process. The use of stories and fairy tales in the teaching of mathematics motivates students to learn and provides students with an authentic context to understand mathematical concepts and procedures. It is a clear way to incorporate mathematics into other, broader cognitive domains and promotes mathematical discussion in the classroom. The main purpose of this study was to investigate the role that the use of storytelling can play in teaching fractions to third grade students. The study sample consisted of 76 third graders, who attended two primary schools in the city of Florina (Greece). This sample was divided into experimental $(\mathrm{n}=38)$ and control $(n=38)$ group. In this study target-focused teaching stories were used. These stories were written in accordance with the objectives of a new Curriculum for rational numbers teaching. The study results showed that the use of storytelling had a positive effect on students' achievement in fractions, as the experimental group performed significantly better than the control group. The students who benefited most from the use of storytelling were those with medium, especially, with low performance. Finally, the use of storytelling had a positive effect on specific mathematical skills, such as comparing fractions, finding equivalent fractions, creating and manipulating representations and problem solving.
\end{abstract}

Keywords: teaching fractions through storytelling, teaching/learning fractions, students of different achievement levels

\section{Introduction}

\subsection{Advantages of Using Storytelling in Teaching Mathematics}

In the past three decades an increasing interest in using storytelling in mathematics teaching and learning emerged (Hong, 1996; Hellwig, Monroe, \& Jacobs, 2000; Haury, 2001; Mink \& Fraser, 2005; Skoumpourdi \& Mpakopoulou, 2011; Szurmak \& Thuna, 2013). The combination of storytelling and mathematics allows students to use their strong points in one cognitive area to support their learning in another (Thraikill, 1994).

The use of storytelling in teaching mathematics can spark students' interest, reduce their anxiety, engage them in the educational process (Zazkis \& Liljedahl, 2009; O’Neill, Pearce, \& Pick, 2004; Casey, Kersh, \& Young, 2004) and provide an alternative explanation of a mathematical idea or principle (Koellner, Wallace, \& Swackhamer, 2009). Storytelling supports memory, provides learning motivation (Van den Heuvel-Panhuizen, Boogaard \& Doig, 2009; Mink \& Fraser, 2005; Bintz, Moore, Wright, \& Dempsey, 2011; Jennings, Jennings, Richey, \& Dixon-Krauss, 1992; Young, 2001) and improves analytical skills. Teachers can use stories to introduce, explain and discuss mathematical concepts in a memorable way (Zazkis \& Liljedahl, 2009). Integrating storytelling within mathematics teaching develops literacy skills and promotes mathematical language (Wiburne \& Napoli, 2008). Storytelling helps teachers to create a dynamic and interactive learning environment that supports students to make sense of mathematical vocabulary (Bintz \& Moore, 2002).

Students must not only comprehend and learn mathematical concepts but also be able to connect mathematics with everyday life situations and communicate their mathematical knowledge to others (Altieri, 2009). Storytelling can stimulate discussion about ways in which mathematics are associated with everyday situations and students' experiences (Koellner, Wallace, \& Swackhamer, 2009). 
According to Skoumpourdi and Mpakopoulou (2011, p. 199), teachers can use storytelling "to provide a model, illustrate a concept, pose a problem and stimulate an investigation". Storytelling allows teachers to connect students' informal knowledge and experiences with more formal problem-solving procedures. In particular, when main characters of the story are used to pose a mathematical problem, they can engage student's imagination and creativity and create enthusiasm in the classroom (Casey, 2004). Thus, the students' energy is directed towards mathematical knowledge. Moreover, the visual representations in the picture stories stimulate students' imagination (Monroe \& Livingston, 2002; Berkowitz, 2011) and provides "informative story lines that foster children's curiosity" (Wiburne \& Napoli, 2008, p. 2).

The use of storytelling creates a meaningful framework for conducting mathematical discussion (Lewis, Long, \& Mackay, 1993; Anderson, Anderson, \& Shapiro, 2004; Nesmith \& Cooper, 2010; Flevares \& Schiff, 2014; van Oers, 2013; Griffiths \& Clyne, 1991) and introducing mathematical activities. In addition, teacher, through stories, can pose interesting problems to the students and teach them problem-solving strategies.

\subsection{Fraction Difficulties}

Fractions are among the most complex and most important mathematical concepts students come up against during their elementary school years (Behr \& Post, 1992; Behr, Wachsmuth, Post, \& Lesh, 1984; Ni, 2001), as they constitute a foundation for learning algebra (Fennell, Faulkner, Ma, Schmid, Stotsky, Wu et al., 2008). It has also been underlined that learning fractions is one of the most serious obstacles to students' development of mathematical thinking (Behr, Harel, Post, \& Lesh, 1993).

In the last decades researchers have identified many factors that contribute to students' difficulties in learning fractions. Lortie-Forgues, Tian and Siegler (2015) identified seven sources of students' difficulties in fractions. These difficulties involve (1) fraction notation, (2) limited accessibility to fraction magnitude, (3) opacity of fraction arithmetic processes, (4) complicated relations between fractions and whole number arithmetic processes, (5) complicated relations among procedures for different fraction arithmetic operations, (6) opposite direction of effects of multiplying and dividing positive proper fractions, (7) large number of distinct procedures in fraction arithmetic. It has also been proposed that students' weak performance in fractions is due to instructional approaches that teachers use to teach fractions (Lamon, 1999). Teaching fractions focuses more on memorizing procedures than understanding (National Mathematics Advisory Panel, 2008; Lemonidis \& Kaiafa, 2014; Lortie-Forgues, Tian, \& Siegler, 2015). This teaching practice is linked to negative outcomes, as students have difficulty in remembering processes that they learn without understanding. Moreover, when students have not developed conceptual understanding, they usually invent the processes they have forgotten and generate their own (incorrect) algorithms (Lortie-Forgues, Tian, \& Siegler, 2015).

Although many resources have been created to help teachers use storytelling in teaching mathematics, there is little research to show how successful this approach is. Most of the research that has been contacted focuses on students of Preschool Education (Perger, 2011). Flevares and Schiff (2014) underline the need for well-structured research in this field, with clear objectives and systematic methodology. In addition, no research was identified that systematically investigated the potential effects of storytelling on teaching and fraction learning. Finally, this study used target-focused teaching stories written in accordance with the objectives of a new Curriculum for rational numbers teaching (Lemonidis, 2017).

Therefore, the originality of the study lies in the fact that it attempts to systematically investigate the effect of storytelling, through the use of target-focused teaching stories, on the fraction teaching and learning and to explore the students' mathematical skills that may be improved through the use of storytelling.

\subsection{Research Questions}

The research questions for this study were:

1) Does storytelling, as an instructional tool, affect Third Grade Primary Students' achievement in fractions?

2) Which students benefit most from the use of storytelling in teaching fractions?

3) What are the specific mathematical skills that storytelling may positively influence?

\section{Method}

\subsection{Participants}

The study sample consisted of 76 third graders, who attended two primary schools in the city of Florina (Greece) in 2015-2016. This sample was divided into experimental $(n=38)$ and control $(n=38)$ group. None of the participants waw diagnosed with learning disabilities. 


\subsection{Procedure}

The same teacher (the researcher) applied the teaching program to both groups (experimental and control group). Students of both groups (experimental and control) followed the same curriculum for the teaching of fractions (Lemonidis, 2017) and had the same textbook (student book and notebook), which was created by the researchers in accordance with the principles and objectives of the particular curriculum.

When introducing a new mathematical concept to the experimental group, the teacher was reading a teaching story to students while the pictures accompanying the text were displayed. Then, a brief discussion on the content of the story took place in the classroom, while the students were working on math activities related to the story and learning objectives. The Teacher was reading the story in an interactive way that fostered communication to accomplish the goal of meaningful student engagement (Courtade, Lingo, Karp, \& Whithey, 2013; Fisher, Flood, Lapp, \& Frey, 2004). The Students were encouraged to strategically and purposefully interact with both the teacher and the content of the story. This reading experience requires students to be active participants than passive listeners (National Early Literacy Panel, 2008). Subsequently, students explored mathematical concepts through the processing of textbook activities (student book and workbook).

When introducing a new mathematical concept to the control group, the teacher used manipulative materials. The Students worked with objects, area models, fraction walls, fraction strips and number lines to explore fraction concepts. Subsequently, the students approached mathematical concepts through the processing of textbook activities (student book \& workbook).

The teaching Intervention lasted for 4 weeks, 4 times per week, 45 min per session. Consequently, the teaching of the experimental and control group differed in the way of introducing the new concept. 10 days after the teaching intervention, the researchers gave the students the post test.

\subsection{Data Collection Tools}

Pre-test questionnaire. This test was developed by the researchers and included 9 activities related to second grade math. The purpose of this test was to determine whether the experimental and control group were equivalent and to divide the sample of each group into three subgroups (high, medium and low performance group) based on their performance on the test.

Post-test questionnaire. This test was developed by the researchers and included 10 activities and problems that were in line with the teaching objectives of the intervention. These activities were referring to:

a) The part-whole interpretation of fraction

Students were asked to represent fractions as parts of a set or parts of an area model.

Students were asked to associate the visual representation of the fraction with its symbolic representation.

b) Placing fractions on number line diagram

Students were asked to match fractions with their locations on a number line. Students were asked to represent fractions as locations on a number line

c) Creating and manipulating fraction representations

Students were asked to create the representation of a fraction

Students were asked to represent the solutions of a problem or an activity

d) Comparing fractions

Students were asked to compare two fractions

Students were asked to find a fraction that is bigger than another one.

e) Problem solving

Students were asked to solve problems about comparing fractions with common numerator or common denominator.

\subsection{Intervention Materials}

a) Student Book and Workbook. All participants (experimental and control group) received a printed (color print) booklet with all the syllabus. The development of teaching material followed the learning and teaching trajectory of the new curriculum for the teaching of rational numbers, proposed by Charalambos Lemonidis (2016). This curriculum is an integrated proposal for teaching fractions and decimal in Elementary School from the 1st to the 5 th grade. 
The main innovations proposed by this curriculum are summarized below:

Fraction teaching precedes decimal teaching. Rational number teaching starts from fractions in the 3rd grade, while decimal numbers are introduced in the 4 th grade, based on decimal fractions.

Emphasis on understanding. Curriculum emphasizes the understanding of the concept of fraction and the procedures associated with performing fraction operations. It aims at fostering conceptual understanding of the fraction before students learn rules and written algorithms.

Supporting developmental progressions in learning. Concepts presentation follows an evolutionary development that is consistent with students' abilities and is based on Learning Trajectories Approach.

Teaching approaches and tools. The Curriculum emphasizes the use of everyday life contexts, problem solving, storytelling and educational technologies.

Using models to visualize mathematical concepts. The Curriculum proposes the use of many types of fraction models to promote students' understanding. Models (objects, area models, fraction walls, fraction strips, number lines) significantly contribute to the visualization of concepts and relationships that are not always visible in symbolic representations of rational numbers.

Mental calculation and estimation. The curriculum emphasizes the mental calculation and estimation procedures aiming at a fuller understanding of rational numbers. Mental manipulation of numbers, relationships and operations contributes to number sense development and problem-solving skills development (Lemonidis, 2005).

In this study we used the trajectory part that was addressed to 3rd grade students.

The main key points in the learning trajectory are as follows:

- Recognizing and formatting unit fractions

- Recognizing and formatting simple fractions

- Placing fractions on a number line diagram

- Comparing fractions with common numerator or common denominator

- Recognizing and creating equivalent fractions using models

b) Teacher's book.

c) Picture stories (experimental group). The stories that were used in experimental intervention were targetfocused, namely, they were in accordance with the curriculum objectives. These stories constitute a narrative unit that includes seven episodes. The main character of the story has such features that make him sympathetic to students who can identify with him. He is a unit fraction that wants to raise his value in order to be accepted by his parents and teachers. In this effort, two whole numbers, 3 and 5, help him. The Students watch characters' adventures and at the same time they learn fractions and their properties. The Stories give teachers and students the chance to discuss concepts, such as friendship, companionship and diversity.

d) Manipulative materials for experiential learning activities (control group).

\section{Results}

\subsection{Students' Performance in Pre-Test}

The results of initial assessment test showed that there was no statistically significant difference between the two groups (experimental and control group) [U=691.00, $\mathrm{p}>0.05]$. Students' achievement test mean score for the experimental group before the teaching intervention was 6.90 with a standard deviation of 2.157 . The same value was 6.95 with a standard deviation of 2.235 for control group students. These scores indicate that the achievement levels of the two groups were similar at the beginning of the study.

Each group was divided into three subgroups on the basis of student performance in the pre-test. Table 1 shows the descriptive statistics of the three subgroups for each group.

Table 1. Performance of the subgroups in pre-test

\begin{tabular}{lllll}
\hline & \multicolumn{2}{l}{ Experimental group } & \multicolumn{2}{l}{ Control group } \\
\hline Subgroups & $\mathrm{N}$ & $\mathrm{M}(\mathrm{SD})$ & $\mathrm{N}$ & $\mathrm{M}(\mathrm{SD})$ \\
High achievement students & 16 & $8.95(0.82)$ & 18 & $8.90(0.86)$ \\
Medium achievement students & 13 & $6.47(0.70)$ & 11 & $6.33(0.88)$ \\
Low achievement students & 9 & $3.88(0.72)$ & 9 & $3.83(0.83)$ \\
\hline
\end{tabular}


Finally, the subgroups of the experimental group were compared with those of the control group (one to one) to find out if they were equivalent. Due to the small number of observations in each subgroup, non-parametric test was performed using the Mann Whitney test.

The mean score of every subgroup of the experimental group was compared with the corresponding subgroup of the control group. Regarding the results of this comparison presented in Table 2 we can observe that there is no statistically difference in the average performance of the three subgroups of the experimental and control groups.

Table 2. Comparative presentation of the average performance of the three subgroups of the experimental and control groups

\begin{tabular}{llllll}
\hline & \multicolumn{6}{l}{ Experimental group } & \multicolumn{4}{l}{ Control group } \\
\hline Subgroups & $\mathrm{N}$ & $\mathrm{M}(\mathrm{SD})$ & $\mathrm{N}$ & $\mathrm{M}(\mathrm{SD})$ & $\mathrm{p}$ \\
High achievement students & 16 & $8.95(0.82)$ & 18 & $8.90(0.86)$ & $0.986>0.05$ \\
Medium achievement students & 13 & $6.47(0.70)$ & 11 & $6.33(0.88)$ & $0.910>0.05$ \\
Low achievement students & 9 & $3.88(0.72)$ & 9 & $3.83(0.83)$ & $0.931>0.05$ \\
\hline
\end{tabular}

\subsection{Students' Performance in Post-Test}

According to the results of the Kolmogorov Smirnov test for the experimental group [ $\mathrm{df}=38, \mathrm{p}=0.20>0,05]$ and the control group [ $\mathrm{df}=38, \mathrm{p}=0.20>0.05]$, in both research groups, the performance variable is normally distributed. Therefore, parametric control (t-test) was performed. According to the results of the t-test, there was a statistically significant difference in the students' performance between the experimental and control group $[t=2.517, \mathrm{df}=74, \mathrm{p}=0.017<0.05]$. The experimental group students' performance test mean score, was 7.89 with a standard deviation of 1.328 after the intervention. The same value was 6.96 with a standard deviation of 1.842 for the control group students.

Subsequently, the subgroups of the experimental group were compared with those of the control group (one to one) to find out if they were equivalent. Due to the small number of observations in each subgroup, non-parametric test was performed using the Mann Whitney test.

Table 3 shows a comparative presentation of the average performance of the three subgroups of the experimental and control groups.

Table 3. Comparative presentation of the average performance of the three subgroups of the experimental and control groups

\begin{tabular}{llllll}
\hline & \multicolumn{6}{l}{ Experimental group } & \multicolumn{4}{l}{ Control group } \\
\hline Subgroups & $\mathrm{N}$ & $\mathrm{M}(\mathrm{SD})$ & $\mathrm{N}$ & $\mathrm{M}(\mathrm{SD})$ & $\mathrm{p}$ \\
High achievement students & 16 & $9.08(0.62)$ & 18 & $8.57(0.92)$ & $0.0966>0.05$ \\
Medium achievement students & 13 & $7.67(0.13)$ & 11 & $6.27(0.69)$ & $0.000<0.05$ \\
Low achievement students & 9 & $6.08(0.73)$ & 9 & $4.58(0.67)$ & $0.002<0.05$ \\
\hline
\end{tabular}

According to the results, there is no statistically significant difference in high achievement students' performance. Instead, medium and low achievement students of experimental group performed significantly better than the same subgroups of the control group.

A two-way analysis of variance (two-way ANOVA test) was conducted to explore the influence of two independent variables (group and subgroup) on the students' performance in post-test. All effects were statistically significant at the 0.05 significance level. The main effect for "group" yielded an $F$ ratio of $F(1,70)=$ $44.9, \mathrm{p}=0.00<0.05$. The main effect for "subgroup" yielded an $\mathrm{F}$ ratio of $\mathrm{F}(2.70)=147.91, \mathrm{p}=0.00<0.05$. The interaction effect was significant, $\mathrm{F}(2.70)=4.04, \mathrm{P}=0.022<0.05$.

These results indicate that the performance of the students in the experimental group was better than that of the control group, while their performance is also influenced by the group the students belong to (high, medium or low achievement group). 


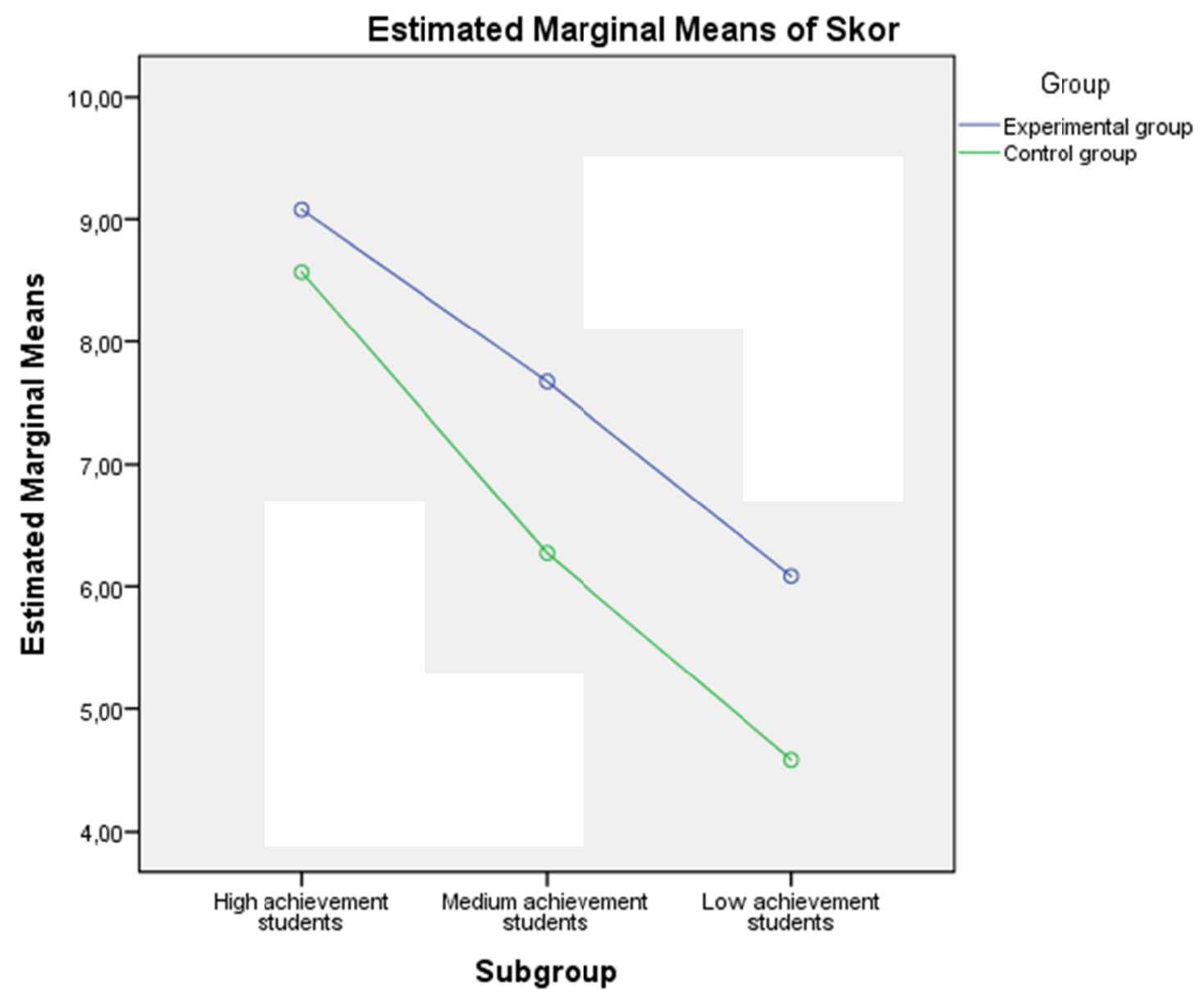

Figure 1. Estimated marginal means of the post-test

\subsection{Students' Performance in Specific Mathematical Skills}

In order to determine the specific mathematical abilities on which the use of storytelling had a positive effect, we classified the activities of the post-test into six categories, based on their content. The categories were as follows: the part-whole interpretation of fraction, number line use, fractionscomparison, fraction equivalence, creating and manipulating fraction representations and problem solving.

As shown in Table 4, the use of storytelling had a positive effect on specific mathematical skills, such as comparing fractions, finding equivalent fractions, creating and manipulating representations and problem solving. There was no statistically significant difference between the two groups in activities that are related to the part-whole interpretation of fraction and to place fractions on the number line. 
Table 4. Comparative presentation of the average performance of two groups in specific mathematical skills

\begin{tabular}{|c|c|c|c|c|c|}
\hline & & $\mathrm{M}$ & $\mathrm{SD}$ & $\mathrm{U}$ & $\mathrm{p}$ \\
\hline \multirow[t]{3}{*}{ Part-whole interpretation of fraction } & & & & 683.50 & 0.574 \\
\hline & Experimentalgroup & 1.87 & 0.30 & & \\
\hline & Control group & 1.83 & 0.33 & & \\
\hline \multirow[t]{3}{*}{ Use of number line } & & & & 676.50 & 0.607 \\
\hline & Experimentalgroup & 1,63 & 0,47 & & \\
\hline & Control group & 1.57 & 0.51 & & \\
\hline \multirow[t]{3}{*}{ Comparing fractions } & & & & 465.00 & 0.007 \\
\hline & Experimentalgroup & 1.84 & 0.44 & & \\
\hline & Control group & 1.50 & 0.54 & & \\
\hline \multirow[t]{3}{*}{ Equivalent fractions } & & & & 551.00 & 0.029 \\
\hline & Experimentalgroup & 0.39 & 0.21 & & \\
\hline & Control group & 0.28 & 0.25 & & \\
\hline Creating and manipulating fraction & & & & 528.50 & 0.040 \\
\hline \multirow[t]{2}{*}{ representations } & Experimentalgroup & 2.16 & 0.67 & & \\
\hline & Control group & 1.79 & 0.79 & & \\
\hline \multirow[t]{3}{*}{ Problem-solving } & & & & 515.50 & 0.025 \\
\hline & Experimentalgroup & 1.47 & 0.40 & & \\
\hline & Control group & 1.19 & 0.55 & & \\
\hline
\end{tabular}

\section{Discussion}

\subsection{Effect of Storytelling on Student Performance in Fractions}

The main purpose of this study was to investigate the role that the use of storytelling can play in teaching fractions to third grade students. The results showed that the use of storytelling had a positive effect on students' achievement in fractions, as the experimental group performed significantly better than the control group. These results are in agreement with the findings of other studies indicating improvement in student performance in mathematics when teacher incorporated storytelling in math teaching (Capraro \& Capraro, 2006a; Casey et al., 2008; Mink \& Fraser, 2005; Bintz et al., 2011; Jennings et al., 1992; Moyer, 2000; Beard, 2003).

There was no statistically significant difference between the two groups on performance of high achieving students. On the contrary, medium achieving students and low achieving students of the experimental group performed significantly better than the corresponding students of the control group. This confirms that students who benefit most from the use of storytelling were the medium and low achieving students.

It seems that the use of storytelling has enhanced these students' interest and motivations (Van den Heuvel-Panhuizen, Boogaard, \& Doig, 2009; Mink \& Fraser, 2005; Bintz et al., 2011; Jennings et al., 1992; Young, 2001). According to U.S. Department of Education (1986, p. 23), "even students with low motivation and weak academic skills are more likely to listen, read, write, and work hard in the context of storytelling". However, even high achieving students can improve their understanding of mathematical concepts by better understanding how those concepts are related to real-life issues (Price, 2009) and the world of imagination.

\subsection{Effect of Storytelling on Specific Mathematical Skills}

The use of storytelling had a positive effect on mathematical skills, such as comparing fractions, finding equivalent fractions, creating and manipulating representations and problem solving. There was no statistically significant difference between the two groups in activities that are related to the part-whole interpretation of fraction and to place fractions on the number line. Finding equivalent fractions and comparing fraction are procedures that require a conceptual understanding of fractions and are associated with the development of fraction sense (Fennell \& Krap, 2016; Carvalho \& da Ponte, 2013). It seems that storytelling contributed to a deeper understanding of mathematical concepts. The story provided students with a familiar and meaningful framework to explore, manipulate and understand mathematical ideas, concepts and procedures (Griffiths \& Clyne, 1991). The story made abstract concepts more concrete, while the integration of concepts within a meaningful context contributed both to the understanding of mathematical concepts and keeping them in memory (Szurmak \& Thuna, 2013). Storytelling provided students with the structure of a system to remember what they learned and incorporate new knowledge into the existing information system (McLellan, 2006).

The use of storytelling in teaching mathematics allowed students to approach mathematical concepts in a learning environment with rich stimuli that contributed to conceptual understanding of mathematical concepts 
(Capraro \& Capraro, 2006a; Van den Heuvel-Panhuizen, Boogaard, \& Doig, 2009; Whitin \& Whitin, 2001). Students who have difficulty in mathematical concepts can benefit from a didactic approach that is often more entertaining and less intimidating (Price, 2009).

The students of experimental group performed significantly better than those of the control group in terms of creating and manipulating fractional representations. Their representations were clear, which helped them to perform better in comparing fractions, finding equivalent fractions and problem-solving. It seems that the relationship was bidirectional. On the one hand, the students who were able to create clear and correct fractional representations could effectively handle fractions and relationships between them and, on the other hand, those who had understood the meaning of the fraction and the relationships between the fractions, could clearly represent their thinking through the use of shapes. The mental images that created students by the stories provided them with visual representations that gave them extra information about mathematical concepts and helped them to create more vivid representations of fraction (Monroe \& Livingston, 2002; Berkowitz, 2011).

Representations that students created through the use of the stories enriched their mathematical understanding. The students had the opportunity to transform the ideas presented through the stories into their own personal representations. Transforming an idea includes processes, such as rethinking, re-creating and reconstructing it in a new form (Whitin \& Whitin, 2001).

Finally, the students of the experimental group performed significantly better than those of the control group in problem solving. This result is in line with previous studies that found improvement of students' ability in problem solving when teachers used storytelling in teaching mathematics (Casey et al., 2008; Smith, 1996; Jacobs \& Rak, 1997; Melser \& Leitze, 1999; Young \& Marroquin, 2006).

Integrating mathematical concepts and procedures within a meaningful context gave students the opportunity to create richer representations and study the features of the concepts in different circumstances. Moreover, students can make sense of the characteristics of mathematical concepts through the characters' action within the story. Storytelling often connects the mathematical problem-solving process with that involved in understanding the content of a story. It provides teachers with interesting and meaningful information about students' thinking that is sometimes more powerful than separately assessing either mathematical understanding or reading comprehension based on a story (Smith, 1996). As the development of mathematical concepts took place along with the story evolution, students had the opportunity to understand "how fraction behaves", how its value changes, and what they should consider when comparing two fractions with a common numerator or common denominator. Subsequently, students could transfer this knowledge to solving problems with similar content.

As mentioned previously, there was no statistically significant difference between the two groups in activities that are related to the part-whole interpretation of fraction and to place fractions on the number line. The part-whole fraction scheme undoubtedly presents significant advantages, as it is very specific and easily accessible by students, especially when they come into contact with the concept of fraction for the first time. However, the part-whole fractions scheme has some important limitations. Negative fractions cannot be represented in this way, as it is very difficult to imagine fractions with large numerators and denominators, while improper fractions can be confusing within the part-whole interpretation (Mack, 1993; Siegler, Thompson, \& Schneider, 2011).

The fact that the two groups (experimental and control) did not differ in students' performance on the part-whole interpretation of fraction and in the location of fractions on the number line may mean that Third Grade students have difficulty in seeing the fraction as a measurement, who face the number line by the logic of the part-whole interpretation. However, this is a conjecture which requires further investigation.

\subsection{Instructional Implications}

The results from this study suggest that careful selection of a story and its targeted inclusion in teaching can support students' understanding of mathematical concepts. Storytelling provides students with a meaningful context in which they can communicate and discuss the mathematical ideas inherent in the text (McDuffie \& Young, 2003). Students' learning is more successful when material is presented in a way that is meaningful to them (Price, 2009). The context story provides students an opportunity to develop meaningful knowledge of concepts and processes through investigation rather than memorizing (Carparo \& Carparo, 2006).

\section{References}

Altieri, J. L. (2009). Strengthening connections between elementary classroom mathematics and literacy. Teaching Children Mathematics, 15(6), 346-351.

Anderson, A., Anderson, J., \& Shapiro, J. (2004). Mathematical discourse in shared storybook reading. Journal 
for Research in Mathematics Education, 35(1), 5-33. https://doi.org/10.2307/30034801

Beard, L. A. (2003). The effects of integrated mathematics and children's literature instruction on mathematics achievement and mathematics anxiety by gender. Doctoral dissertation, University of Southern Mississippi, Hattiesburg.

Behr, M., Harel, G., Post, T., \& Lesh, R. (1993). Rational Numbers: Toward a SemanticAnalysis-Emphasis on the Operator Construct. In T. Carpenter, E. Fennema \& T. Romberg (Eds.), Rational Numbers: An Integration of Research (pp. 13-47). Hillsdale, NJ: Lawrence Erlbaum Associates.

Behr, M., \& Post, T. (1992). Teaching rational number and decimal concepts. In T. Post (Ed.), Teaching mathematics in grades K-8: Research-based methods (2nd ed.) (pp. 201-248). Boston: Allyn and Bacon.

Behr, M. J., Wachsmuth, I., Post, T. R., \& Lesh, R. (1984). Order and equivalence of rational numbers: A clinical teaching experiment. Journal for Research in Mathematics Education, 15(5), 323-341. https://doi.org/10.2307/748423

Berkowitz, D. (2011). Oral storytelling building community through dialogue, engagement, and problem solving. Young Children, 66(2), 36-40.

Bintz, W. P., \& Moore, S. D. (2002). Using literature to support mathematical thinking in middle school. Middle School Journal, 34(2), 25-32. https://doi.org/10.1080/00940771.2002.11495350

Bintz, W. P., Moore, S. D., Wright, P., \& Dempsey, L. (2011). Using literature to teach measurement. The Reading Teacher, 65(1), 58-70.

Capraro, R. M., \& Capraro, M. M. (2006). Are You Really Going to Read Us A Story? Learning Geometry Through Children's Mathematics Literature. Reading Psychology, 27(1), 21-36. https://doi.org/10.1080/02702710500468716

Carvalho, R., \& da Ponte, J. P. (2013). Student's mental computation strategies with rational numbers represented as fractions. Paper presented at Eighth Congress of European Research in Mathematics Education (CERME 8), Antalya.

Casey, B. (2004). Mathematics problem-solving adventures: A language-arts-based supplementary series for early childhood that focuses on spatial sense. In D. Clements \& J. Samara (Eds.), Engaging young children in mathematics: Standards for early childhood mathematics education (pp. 377-389). Mahwah, NJ: Lawrence Erlbaum.

Casey, B., Erkut, S., Ceder, I., \& Young, J. M. (2008). Use of a storytelling context to improve girls' and boys' geometry skills in kindergarten. Journal of Applied Developmental Psychology, 29, 29-48. https://doi.org/10.1016/j.appdev.2007.10.005

Casey, B., Kersh, J., \& Young, J., (2004). Storytelling sagas: An effective medium for teaching early childhood mathematics. Early Childhood Research Quarterly, 19(1), 167-172. https://doi.org/10.1016/j.ecresq.2004.01.011

Courtade, G. R., Lingo, A. S., Karp, K. S., \& Whitney, T. (2013). Shared story reading. Teaching Mathematics to Students with Moderate and Severe Disabilities. Teaching Experimental Children, 45, 34-44. https://doi.org/10.1177/004005991304500304

Fennell, F. S., Faulkner, L. R., Ma, L., Schmid, W., Stotsky, S., Wu, H.-H., et al. (2008). Report of the Task Group on Conceptual Knowledge and Skills. Washington DC: U.S. Department of Education, The Mathematics Advisory Panel.

Fennell, F., \& Karp, K. (2016). Fraction Sense: Foundational Understandings. Journal of Learning Disabilities, 50(6), 648-650. https://doi.org/10.1177/0022219416662030

Fisher, D., Flood, J., Lapp, D., \& Frey, N. (2004). Interactive read-alouds: Is there a common set of implementation practices? The Reading Teacher, 58(1), 8-17. https://doi.org/10.1598/RT.58.1.1

Flevares, L. M., \& Schiff, J. L. (2014). Learning mathematics in two dimensions: A review and look ahead at teaching and learning early childhood mathematics with children's literature. Frontiers in Psychology, 5, 112. https://doi.org/10.3389/fpsyg.2014.00854

Griffiths, R., \& Clyne, M. (1991). The power of story: Its role in learning mathematics. Math Teaching, 135, 4245.

Haury, D. (2001). Literature-based mathematics in elementary school. ERIC Digest. Columbus, OH: ERIC 
Clearinghouse for Science, Mathematics, and Environmental Education.

Hellwig, S. J., Monroe, E. E., \& Jacobs, J. S. (2000). Making informed choices: Selecting children's tradebooks for mathematics instruction. Teaching Children Mathematics, 7(3), 138-143.

Hong, H. (1996). Effects of Mathematics learning Through Children's literature on Math Achievement and Dispositional Outcomes. Early Childhood Research Quarterly, 11, 477-494. https://doi.org/10.1016/S0885-2006(96)90018-6

Jacobs, A., \& Rak, S. (1997). Mathematics and Literature: A winning combination. Teaching Children Mathematics, 4(3), 156-157.

Jennings, C. M., Jennings, J. E., Richey, J., \& Dixon-Krauss, L. D. (1992). Increasing interest and achievement in mathematics through children's literature. Early Childhood Research Quarterly, 7(2), 263-276. https://doi.org/10.1016/0885-2006(92)90008-M

Koellner, K., Wallace, F. H., \& Swackhamer, L. (2009). Integrating literature to support mathematics learning in middle school. Middle School Journal, 41(2), 30-39. https://doi.org/10.1080/00940771.2009.11461710

Lamon, S. J. (1999). Teaching Fractions and Ratios for Understanding. New Jersey: Lawrence Erlbaum Associates.

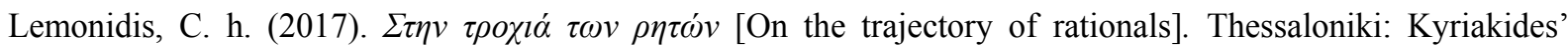
editions.

Lemonidis, C. h. (2015). Mental Computation and Estimation: Implications for mathematics education research, teaching and learning. Routledge. https://doi.org/10.4324/9781315675664

Lemonidis, C. h., \& Kaiafa, I. (2014). Fifth and sixth grade students' number sense in rational numbers and its relation with problem solving ability. MENON: Journal of Educational Research (1st Thematic Issue), 6174.

Lewis, B. L., Long, R., \& Mackay, M. (1993). Fostering communicating in mathematics using children's literature. Arithmetic Teacher, 40(8), 470-474.

Lortie-Forgues, H., Tian, J., \& Siegler, R. S. (2015). Why is learning fraction and decimal arithmetic so difficult? Developmental Review, 38, 201-221. https://doi.org/10.1016/j.dr.2015.07.008

Mack, N. K. (1993). Learning rational numbers with understanding. The case of informal knowledge. In T. P. Carpenter, E. Fennema \& T. A. Romberg (Eds.), Rational numbers: An integration of research (pp. 85-105). Hillsdale, NJ: Erlbaum.

McDuffie, A. M. R., \& Young, T. A. (2003). Promoting mathematical discourse through children's literature. Teaching Children Mathematics, 9, 385-389.

McLellan, H. (2006). Corporate storytelling perspectives. Journal for Quality and Participation, 29, 17-20.

Melser, N., \& Leitze, A. (1999). Connecting Language Arts and Mathematical Problem Solving in the Middle Grades. Middle School Journal, 31(1), 48-54. https://doi.org/10.1080/00940771.1999.11494609

Mink, D. V., \& Fraser, B. J. (2005). Evaluation of a K-5 mathematics program which integrates children's literature: Classroom environment and attitudes. International Journal of Science and Mathematics Education, 3, 59-85. https://doi.org/10.1007/s10763-004-2975-0

Monroe, E. E., \& Livingston, N. (2002). It figures: Language and mathematics add up through children's literature. The Dragon Lode, 20(2), 37-41.

Moyer, P. S. (2000). A remainder of one: Exploring partitive division. Teaching Children Mathematics, 6(8), 517.

National Early Literacy Panel. (2008). Developing early literacy: Report of the national early literacy panel. Washington, DC: National Institute for Literacy.

National Mathematics Advisory Panel. (2008). Foundations for success: The final report of the National Mathematics Advisory Panel. Washington, DC: U.S. Department of Education.

Nesmith, S., \& Cooper, S. (2010). Trade books in the mathematics classroom: The impact of many, varied perspectives on determinations of quality. Journal of Research in Childhood Education, 24(4), 279-297. https://doi.org/10.1080/02568543.2010.510086

$\mathrm{Ni}$, Y. (2001). Semantic domains of rational numbers and the acquisition of fraction equivalence. Contemporary Educational Psychology, 26, 400-417. https://doi.org/10.1006/ceps.2000.1072 
O’Neill, D. K., Pearce, M. J., \& Pick, J. L. (2004). Preschool children's narratives and performance on the Peabody Individualized Achievement Test—Revised: Evidence of a relation between early narrative and later mathematical ability. First Language, 24(2), 149-183. https://doi.org/10.1177/0142723704043529

Perger, P. (2011). Identifying mathematics in children's literature: Year seven student's results. In J. Clark, B. Kissane, J. Mousley, T. Spencer \& S. Thornton (Eds.), Mathematics: Traditions and [new] practices. Proceedings of the 34th annual conference of the Mathematics Education Research Group of Australasia. Adelaide: MERGA.

Price, R. R. (2009). Using Children's Literature to Teach Mathematics. NC: Quantile.

Siegler, R. S., Thompson, C. A., \& Schneider, M. (2011). An integrated theory of whole number and fractions development. Cognitive Psychology, 62, 273-296. https://doi.org/10.1016/j.cogpsych.2011.03.001

Skoumpourdi, C., \& Mpakopoulou, I. (2011). The Prints: A Picture Book for Pre-Formal Geometry. Early Childhood Education Journal, 39, 197-206. https://doi.org/10.1007/s10643-011-0454-0

Smith, J. J. (1996). Counting on Company Row. Teaching Children Mathematics, 3(1), 34-38.

Szurmak, J., \& Thuna, M. (2013). Tell Me a Story: The Use of Narrative as a Tool for Instruction. Indianapolis, $I N, 546-552$.

Thrailkill, C. (1994). Math and literature: A perfect match. Teaching K-8, 24, 64-65.

U.S. Department of Education. (1986). What works: Research about teaching and learning. Washington, DC: Author.

Van den Heuvel-Panhuizen, M., Boogaard, S., \& Doig, B. (2009). Picture Books Stimulate the Learning of Mathematics. Australian Journal of Early Childhood, 34(3), 30-39.

van Oers, B. (2013). Communicating about number: Fostering young children's mathematical orientation in the world. In L. D. English \& J. T. Mulligan (Eds), Reconceptualizing Early Mathematics Learning (pp. 183203). New York: Springer. https://doi.org/10.1007/978-94-007-6440-8_10

Whitin, P., \& Whitin, D. (2001). Using literature to invite mathematical representations. In A. A. Cuoco (Ed.), The roles of representation in school mathematics (2001 yearbook of the National Council of Teachers of Mathematics, pp. 228-237). Reston, VA: National Council of Teachers of Mathematics.

Wilburne, J. M., \& Napoli, M. (2008). Connecting Mathematics and literature: An analysis of pre-service education school teachers' changing beliefs and knowledge. IUMPST: The Journal, 2, 1-10.

Young, J. E. (2001). Why are we reading a book during math time? How mathematics and literature relate. The Dragon Lode. IRA Children's Literature and Reading Special Interest Group, 19(2), 13-18.

Young, E., \& Marroquin, C. (2006). Posing problems from children's literature. Teaching Children Mathematics, $12,362-366$.

Zazkis, R., \& Liljedahl, P. (2009). Teaching Mathematics as Storytelling. Rotterdam, The Netherlands: Sense Publishers. https://doi.org/10.1163/9789087907358

\section{Copyrights}

Copyright for this article is retained by the author, with first publication rights granted to the journal.

This is an open-access article distributed under the terms and conditions of the Creative Commons Attribution license (http://creativecommons.org/licenses/by/4.0/). 